\title{
Avaliação do potencial antioxidante da geleia real ao longo do tempo de armazenamento
}

\author{
Renata Galhardo Borguini ${ }^{1}$ \\ Fernanda Duarte ${ }^{2}$ \\ Maria Luisa Teles Marques Florêncio Alves ${ }^{3 *}$ \\ Erica Weinstein Teixeira ${ }^{3}$ \\ Augusta Carolina de Camargo Carmello Moreti ${ }^{4}$
${ }^{1}$ Empresa Brasileira de Pesquisa Agropecuária - EMBRAPA, Embrapa Agroindústria de Alimentos
${ }^{2}$ Universidade de Taubaté, Departamento de Ciências Agrárias, Engenharia de Alimentos ${ }^{3}$ Secretaria de Agricultura e Abastecimento do Estado de São Paulo
Agência Paulista de Tecnologia dos Agronegócios, Pólo Regional do Vale do Paraíba
${ }^{4}$ Instituto de Zootecnia, Sede-Nova Odessa
* Autor para correspondência
marialuisa@apta.sp.gov.br \\ Av. Prof. Manoel César Ribeiro, 320, Caixa Postal 07, CEP 12400-970, Pindamonhangaba - SP, Brasil
}

\section{Resumo}

A geleia real é uma substância com aspecto de pasta gelatinosa, de cor branca, ligeiramente amarelada, secretada pelas glândulas hipofaringeanas e mandibulares das abelhas operárias. O objetivo desta pesquisa foi avaliar o potencial antioxidante da geleia real, ao longo do tempo de armazenamento. Os parâmetros físico-químicos utilizados foram: umidade, teor de ácido ascórbico e de fenólicos totais. As amostras foram submetidas ao processo de extração dando origem ao extrato alcoólico, que foi aplicado ao teste do 1,1-difenil2-picrilhidrazil (DPPH) para avaliação da atividade antioxidante in vitro. A geleia real apresentou baixos teores de ácido ascórbico (de 0,75 a 1,31 mg.100 $\mathrm{g}^{-1}$ base úmida) e de fenólicos totais (de 14,26 a 28,30mg EAG.100 $\mathrm{g}^{-1}$ base úmida). As porcentagens de descoloração do DPPH pelo extrato alcoólico das amostras ficaram acima de $50 \%$, exceto aos 90 dias de armazenamento. A partir dos resultados obtidos, considerando-se os reduzidos teores de ácido ascórbico e de fenólicos totais e, ainda, o baixo desempenho do extrato alcoólico das amostras no teste de atividade antioxidante in vitro, conclui-se que a geleia real apresenta potencial antioxidante relativamente baixo. $\mathrm{O}$ tempo de armazenamento não foi determinante nas alterações encontradas.

Palavras-chave: Ácido Ascórbico; Compostos fenólicos; Umidade

\section{Abstract}

Evaluation of the antioxidant potential of royal jelly during storage. Royal jelly is a creamy substance produced by young nurse worker bees, which has a color that ranges from white to slightly yellow, and is secreted by the hypopharingeal and mandibular glands of the bees. The objective of this work was to assess the in vitro antioxidant potential of royal jelly while in storage. The physical-chemical parameters analyzed 
were moisture, ascorbic acid and total phenolic content. Alcohol extracts were made and used to evaluate the 1.1-diphenyl-2-picrylhydrazyl (DPPH) radical scavenging activity. The ascorbic acid (to 0.75 from $1.31 \mathrm{mg}^{-100 \mathrm{~g}^{-1}}$ wet base) and total phenolic content (to 14.26 from $28.30 \mathrm{mg} \mathrm{GAE} 100 \mathrm{~g}^{-1}$ wet base) of the royal jelly were low. The percentages of DPPH discoloration of the samples were above 50\%, except for the samples stored for 90 days. Considering the reduced ascorbic acid and total phenolic content, and the low alcohol DPPH scavenging activity of the samples, it can be concluded that royal jelly presents relatively low antioxidant potential. The storage time did not determine the changes found.

Key words: Ascorbic acid; Moisture; Phenolic content

\section{Introdução}

Segundo Krell (1996), a definição exata de geleia real está relacionada ao método de produção, sendo, portanto, o produto da secreção do sistema glandular cefálico (glândulas hipofaringeanas e mandibulares) das abelhas operárias, coletado até 72 horas, depois de ocorrida a transferência da larva (BRASIL, 2001). Essas glândulas, situadas na cabeça do inseto, têm a produção máxima nas abelhas jovens, sendo aquelas de idade entre três e dez dias as mais produtivas. A geleia real é oferecida como alimento para as larvas de todas as castas (operária, zangão e rainha) até o terceiro dia de vida, bem como para a rainha durante toda a sua vida (MARCHINI, 1995).

A geleia real constitui o único alimento da abelha rainha. $\mathrm{O}$ valor nutritivo potencial dessa substância evidencia-se pelo fato de ela produzir um indivíduo (a rainha), anatômica e fisiologicamente diferente de outro (a operária), que pertence ao mesmo sexo (feminino) e é proveniente do mesmo tipo de ovo fecundado. Além disso, deve-se considerar a grande longevidade da rainha, que pode viver até cinco anos, enquanto a operária vive, em média, seis ou sete semanas (KERR; AMARAL, 1960).

Por muitos anos a geleia real foi utilizada como alimento exclusivo das abelhas, mas com o passar do tempo o homem passou a utilizá-la como cosmético ou suplemento alimentar, devido à crença de que ela exerce efeito similares em seres humanos (MARCHINI, 1995; JAMNIK et al., 2007).

Por ser um produto de difícil obtenção, uma vez que é produzida em quantidades pequenas, e de grande procura, devido aos benefícios que são atribuídos ao seu uso, a geleia real alcança preço considerável no comércio, sendo comuns os episódios de adulteração do produto, por adição de substâncias com o intuito de aumentar o volume. Um dos adulterantes mais comumente utilizados é a água (AMOEDO; MURADIAM, 2002).

O potencial antioxidante da geleia real pode ser expresso pela quantidade de substâncias antioxidantes presentes, como o ácido ascórbico e compostos fenólicos. A importância dessas substâncias para a saúde fundamenta-se na capacidade de inibir ou retardar a formação e a ação deletéria de certos compostos oxidantes, provenientes do metabolismo do oxigênio molecular, popularmente conhecidos como radicais livres (ISHIMOTO, 2003).

Devido à perecibilidade, geralmente o produto é armazenado e comercializado a baixas temperaturas. Pelo fato de não haver uma determinação específica com relação à validade comercial, persistem dúvidas sobre a preservação do valor nutritivo e, principalmente, sobre a manutenção das propriedades antioxidantes da geleia real ao longo do período de armazenamento.

Considerando-se o valor nutritivo da geleia real e, ainda, a escassez de informações sobre o produto, a presente pesquisa teve como objetivo avaliar o potencial antioxidante da geleia real, ao longo do tempo de armazenamento.

\section{Material e Métodos}

\section{Obtenção das amostras}

As amostras de geleia real foram obtidas junto ao apiário experimental do Pólo Regional de Desenvolvimento Tecnológico dos Agronegócios do Vale do Paraíba, localizado na cidade de Pindamonhangaba - SP (22 $\left.57^{\prime} \mathrm{S}, 4^{\circ} 27^{\prime} \mathrm{W}, 560 \mathrm{~m}\right)$, órgão pertencente 
à Agência Paulista de Tecnologia dos Agronegócios (APTA) da Secretaria de Agricultura e Abastecimento do Estado de São Paulo.

A geleia real foi obtida a partir de um sistema de produção comercial de abelhas rainhas, que teve como base o método Doolittle (1899), com modificações. Larvas de 24 a 36 horas foram transferidas, com auxílio de uma agulha de enxertia articulada (tipo chinesa), para cúpulas de cera fixadas, espaçadamente, em barras portacúpulas (20 cúpulas por barra). Os dois quadros contendo as barras porta-cúpulas (duas barras por quadro, totalizando 40 cúpulas) foram introduzidos em seis colmeias recrias órfãs (sem rainha), onde permaneceram de 64 a 66 horas, ocasião em que a geleia real foi colhida.

Durante todo o período experimental, as colmeias foram manejadas visando à manutenção do status populacional adequado à produção de geleia real. Desse modo, foi mantida a proporção de quatro a cinco quadros de cria operculada ou cria nascente (crias que se encontram em células seladas, na fase final do processo de metamorfose, próximo à emergência ou nascimento), um a dois quadros de cria não operculada (crias em fase larval, que ainda recebem alimentação), um a dois quadros de alimentos. Semanalmente, em caso de necessidade de suplementação alimentar, devido à escassez de alimento no campo, os enxames receberam $3 \mathrm{~L}$ de alimento energético (xarope de açúcar a $60 \%$ ) em alimentador tipo Boardman e $100 \mathrm{~g}$ de substituto protéico, elaborado com pólen, farinha de soja desengordurada (1:3) e xarope de açúcar (1:1), colocado sobre os quadros de cria, em sacos plásticos com fendas, para facilitar o acesso das abelhas.

Em outra área, durante todo o período experimental, foi mantido um apiário de apoio, com 30 colmeias, com o objetivo de oferecer ou receber os quadros de cria necessários para permitir o manejo proposto.

A geleia real foi retirada das realeiras com o auxílio de uma pequena espátula de plástico descartável, transferida para frasco de vidro protegido da luz e, imediatamente, armazenada em freezer a $-18^{\circ} \mathrm{C}$.

Cada amostra foi constituída por dois lotes, sendo cada lote composto da geleia real proveniente de dois ciclos de produção consecutivos, uma vez que em cada ciclo obtinha-se $37,5 \mathrm{~g}$ do produto, a quantidade mínima para os procedimentos analíticos era $75 \mathrm{~g}$ os 6 intervalos de tempo propostos $(12,5 \mathrm{~g}$ de amostra para cada intervalo de tempo). As amostras foram analisadas no decorrer do período de armazenamento, considerando-se os seguintes intervalos de tempo: 0, 15, 30, 60, 90 e 120 dias. O limite de 120 dias foi estabelecido em função da quantidade de amostra necessária para as análises e considerando-se que foram efetuadas duas repetições, para cada intervalo de tempo.

\section{Análises físico-químicas}

As amostras foram descongeladas em temperatura ambiente, homogeneizadas e pesadas nas respectivas quantidades para a realização das diversas análises.

a) Umidade: foi determinada segundo protocolo analítico da AOAC (1996, apud INSTITUTO ADOLFO LUTZ, 2008). Pesou-se 5g de amostra, que permaneceu em estufa a vácuo a $70^{\circ} \mathrm{C}$, seguido de pesagem até peso constante. Os resultados foram expressos em porcentagem de água da amostra.

b) Teor de ácido ascórbico: foi determinado segundo protocolo analítico da AOAC (1984). Pesou-se $5 \mathrm{~g}$ da amostra de geleia real, a qual foi diluída em $25 \mathrm{~mL}$ de ácido oxálico a $0,2 \%$. Após agitação para homogeneização, foi tomada uma alíquota de $10 \mathrm{~mL}$, que foi transferida para erlenmeyer de $125 \mathrm{~mL}$ e adicionado $10 \mathrm{~mL}$ de ácido oxálico, que na sequência foi titulada com Reativo de Tillmans (2,6 diclorofenol-indofenol), até a obtenção de uma coloração ligeiramente rosada e estável por 15 segundos. Os teores de ácido ascórbico das amostras foram calculados tomando-se por base um padrão de ácido ascórbico, previamente determinado. Os resultados foram expressos em $\mathrm{mg}$ de ácido ascórbico por $100 \mathrm{~g}$ de amostra.

c) Teor de fenólicos totais: foi realizada de acordo com Singlenton e Rossi (1965). Para a obtenção dos extratos, foram pesados $2,5 \mathrm{~g}$ da amostra, ao qual foram adicionados $35 \mathrm{~mL}$ de etanol $70 \%$ (v/v). Em seguida, agitou-se em homogeneizador magnético por 45 minutos a temperatura ambiente e ao abrigo da luz. A solução foi filtrada em papel filtro e o 
TABELA 1: Teor de umidade, ácido ascórbico, fenólicos totais da geleia real e atividade antioxidante, expressa pela porcentagem de descoloração do DPPH, do extrato alcoólico (concentração $6,5 \mathrm{mg}^{-\mathrm{mL}^{-1}}$ ).

\begin{tabular}{ccccc}
\hline $\begin{array}{c}\text { Tempo de armazenamento } \\
(\text { dias })\end{array}$ & $\begin{array}{c}\text { Unidade* } \\
(\%)\end{array}$ & $\begin{array}{c}\mathrm{AA}^{*} \\
\left(\mathrm{mg} \cdot 100 \mathrm{~g}^{-1}\right)^{* *}\end{array}$ & $\begin{array}{c}\mathrm{FT}^{*} \\
\left(\mathrm{mg} \mathrm{EAG.100 \textrm {g } ^ { - 1 }}\right)^{* *}\end{array}$ & $\begin{array}{c}\text { Descoloração do DPPH* } \\
(\%)\end{array}$ \\
\hline 0 & $67,45^{\mathrm{b}}$ & $1,31^{\mathrm{a}}$ & $25,23^{\mathrm{ab}}$ & $55,03^{\mathrm{abc}}$ \\
15 & $68,56^{\mathrm{ab}}$ & $1,18^{\mathrm{a}}$ & $24,64^{\mathrm{ab}}$ & $52,95^{\mathrm{bc}}$ \\
30 & $69,08^{\mathrm{a}}$ & $0,96^{\mathrm{ab}}$ & $27,67^{\mathrm{a}}$ & $61,30^{\mathrm{ab}}$ \\
60 & $68,35^{\mathrm{ab}}$ & $0,96^{\mathrm{ab}}$ & $28,30^{\mathrm{a}}$ & $54,73^{\mathrm{abc}}$ \\
90 & $68,80^{\mathrm{ab}}$ & $0,75^{\mathrm{b}}$ & $23,17^{\mathrm{b}}$ & $45,56^{\mathrm{c}}$ \\
120 & $68,78^{\mathrm{ab}}$ & $1,01^{\mathrm{ab}}$ & $14,26^{\mathrm{c}}$ & $64,71^{\mathrm{a}}$ \\
\hline
\end{tabular}

*Os valores representam médias de seis determinações. **Resultados apresentados em base úmida. Médias seguidas de mesma letra não possuem diferença significativa ao nível de 5\% de probabilidade. AA: ácido ascórbico; FT: fenólicos totais; EAG: equivalente de ácido gálico. Valor de \% de descoloração do DPPH pelo BHT a 0,2 mg.mL $\mathrm{m}^{-1}=91,88 \%$.

já era esperado, por ser um produto das glândulas hipofaringeanas e mandibulares de abelhas operárias da mesma espécie (Apis mellifera). De acordo com Crane (1990), a composição da geleia real, pode não ser diretamente afetada, mantendo-se relativamente constante quando comparada com valores obtidos na análise de diferentes colônias, subspécies, raças, período de produção das abelhas e pela alimentação por se tratar de uma substancia secretada por glândulas especificas, ao contrario dos demais produtos apícolas, que são elaborados a partir de transformações de compostos coletados das plantas.

De acordo com os resultados apresentados na Tabela 1, o teor de ácido ascórbico da amostra aos 90 dias de armazenamento foi significativamente inferior $(p<0,05)$ ao das amostras armazenadas por zero e quinze dias. Para os demais resultados não houve diferença significativa $(\mathrm{p}>0,05)$.

A geleia real apresentou baixo teor de ácido ascórbico, quando comparado aos valores encontrados para amostras de pólen. Oliveira et al. (2006) encontraram teores de vitamina C que variam entre 53,7 a $56 \mathrm{mg} .100 \mathrm{~g}^{-1}$ de pólen. Não foram encontrados dados na literatura sobre o conteúdo de ácido ascórbico em geleia real.

Quanto aos teores de fenólicos totais (Tabela 1), pode-se observar que a amostra armazenada por 90 dias apresentou menor quantidade em relação àquelas armazenadas por 30 e 60 dias. A geleia real armazenada pelo maior período de tempo (120 dias) apresentou teor inferior de fenólicos totais em comparação às demais amostras.

Este estudo revela que a geleia real é um alimento com baixo teor de fenólicos totais, quando comparado ao pólen. Carpes et al. (2008) avaliaram o potencial antioxidante do pólen apícola produzido na Região Sul do Brasil e obtiveram teores médios de fenólicos totais de $3000,77 \mathrm{mg}$ EAG por $100 \mathrm{~g}$ de pólen. Segundo Ramadan e Al-Ghamdi (2012), a atividade biológica da geleia real é atribuída, principalmente, aos ácidos graxos, proteínas e compostos fenólicos.

Os valores de fenólicos totais e ácido ascórbico da geleia real, provavelmente, estão relacionados à presença de pólen, uma vez que tais substâncias são oriundas do metabolismo secundário de plantas. De acordo com Krell (1996), água, proteínas, lipídios e carboidratos são os mais importantes componentes da geleia real, mas fragmentos de exúvias de larvas, cera e os grãos de pólen de plantas visitadas pelos operatrias constituem cerca de $5 \%$ do peso nas amostras da geleia real.

A contaminação da geleia real por pólen pode ter ocorrido na própria colmeia, uma vez que as abelhas forrageadoras continuam a coletar néctar e pólen, materiais básicos para o crescimento larval, a metamorfose e o desenvolvimento do adulto e as suas atividades. Adicionalmente, há ainda a possibilidade de contaminação devido à presença de grãos de pólen no mel, alimento utilizado como recurso energético pelo inseto, além da possibilidade de contaminação durante o processo de regurgitamento, podendo esses grãos estar presentes no conteúdo do papo ou partes do aparelho 
bucal das abelhas jovens que a secretam. Barth (2005), realizando análise polínica em geleia real, verificou que amostras oriundas de colmeias instaladas em um mesmo local mostram tipos polínicos semelhantes, mas em diferentes porcentagens, indicando que as colônias buscam recursos florísticos preferenciais. Morgado et al. (2008) concluíram, a partir de amostras de geleia real produzidas na mesma localidade do presente estudo (apiários experimentais da APTA, em Pindamonhangaba), que a identificação dos tipos polínicos presentes no produto pode, inclusive, ser utilizada como indicativo para adulterações e falsas indicações a respeito da procedência da geleia real colocada no comércio. Pelo reconhecimento da vegetação através da análise polínica, é possível levantar associações fitogeográficas que caracterizam determinada região, estabelecendo grupos de vegetação indicadores através do tipo de pólen encontrado nas amostras, o que pode revelar a região de produção, considerando-se a composição florística do local (MORGADO et al., 2008).

\section{Teste de atividade antioxidante in vitro}

Observou-se que houve diferença significativa entre as amostras no tempo de armazenamento de 15 e 120 dias, 30 e 90 dias, 90 e 120 dias (Tabela 1). A porcentagem de descoloração do DPPH pelo extrato alcoólico para a maioria das amostras ficou acima de $50 \%$, exceto em 90 dias de armazenamento. Comparando os resultados obtidos para os extratos da geleia real a $6,5 \mathrm{mg} \cdot \mathrm{mL}^{-1}$ com o resultado do padrão do ensaio (BHT) a $0,2 \mathrm{mg} \cdot \mathrm{mL}^{-1}$, pode-se inferir que a geleia real apresenta potencial antioxidante relativamente baixo.

Segundo Buratti et al. (2007), dentre os produtos apícolas, a própolis tem a maior atividade antioxidante, seguido da geleia real e do mel.

Pode-se inferir que o método utilizado para conservação da geleia real (congelamento a $-18^{\circ} \mathrm{C}$ ) ao longo dos 120 dias de armazenamento foi eficiente, pois, apesar do potencial antioxidante relativamente baixo, os resultados permaneceram sem alterações expressivas ao longo do tempo de armazenamento. As diferenças observadas devem-se, provavelmente, à diversidade dos lotes utilizados para amostragem e não ao tempo de armazenamento. Tal procedimento justificou-se pela impossibilidade de atender, com um mesmo lote de produção, às quantidades do produto necessárias para todas as replicatas analíticas. Considerando-se a pequena quantidade que é naturalmente produzida pelas colmeias e o grande número de colmeias de apoio necessárias para manutenção do status populacional das recrias de produção, conforme já exposto, não foi possível proceder de forma diferente, senão adotando-se a estratégia de repetições no tempo, mesmo em se tratando de utilização de estrutura de um Sistema de Produção Industrial de abelhas rainhas. Ressalta-se que a quantidade necessária foi obtida no menor espaço de tempo possível.

Considerando-se os reduzidos teores de ácido ascórbico e de fenólicos totais e, ainda, o baixo desempenho do extrato alcoólico das amostras no teste de atividade antioxidante in vitro, conclui-se que a geleia real apresenta potencial antioxidante relativamente baixo. Considerando-se o tempo de armazenamento, pode-se concluir que esse fator não foi determinante das alterações encontradas.

\section{Agradecimentos}

À Fundação de Desenvolvimento Administrativo (FUNDAP) pela concessão de bolsa à Fernanda Duarte.

\section{Referências}

AOAC - ASSOCIATION OF OFFICIAL ANALYTICAL CHEMISTS. Official methods of analysis. Washington: AOAC, 1984. 1018 p.

AOAC - ASSOCIATION OF OFFICIAL ANALYTICAL CHEMISTS. Official methods of analysis. 16 ed. Arlington: AOAC, 1995. 1298 p.

AMOEDO, L. H. G.; MURADIAN, L. B. A. Comparação de metodologias para determinação de umidade em geleia real. Química Nova, São Paulo, v. 25, n. 4, p. 676-679, 2002.

BARTH, O. M. Botanical resources used by Apis mellifera determined by pollen analysis of royal jelly in Minas Gerais, Brazil Journal of Apicultural Research, Cardiff, v. 44, n. 2, p. 78-81, 2005.

BURATTI, S.; BENEDETTI, S.; COSIO, M. S. Evaluation of the antioxidant power of honey, propolis and royal jelly by amperometric flow injection analysis. Talanta, Amsterdam, v. 71, p. 1387-1392, 2007.

BRAND-WILLIAMS, W.; CUVELIER, M. E.; BERSET, C. Use of a free radical method to evaluate antioxidant activity. LebensmittelWissenschaft \& Technologie, London, v. 28, p. 25-30, 1995. 
BRASIL - MINISTÉRIO DA AGRICULTURA E DO ABASTECIMENTO. Regulamento técnico de identidade e qualidade de apitoxina, cera de abelha, geleia real, geleia real liofilizada, pólen apícola, própolis e extrato de própolis. 2001. Portaria $\mathrm{n}^{\mathrm{o}}$ 574, de 8 de dezembro de 1998, Instrução Normativa no 3 de 19 de janeiro 2001. Publicada no DOU de 23 de janeiro de 2001 e, seção 1, p. 18-23.

CARPES, S. T.; PRADO, A.; MORENO, I. A. M.; MOURÃO, G. B.; ALENCAR, S. M.; MASSON, M. L. Avaliação do potencial antioxidante do pólen apícola produzido na Região Sul do Brasil. Química Nova, São Paulo, v. 31, n. 7, p. 1660-1664, 2008.

CRANE, E. The newer hive products: pollen, propolis, royal jelly, be venom, bee brood. In: CRANE, R. (Ed.). Bees and beekeeping science practive and wolr resourses. Ithaca: Comstock Publishing Associales, 1990. p. 452-465.

DOOLITTLE, G. M. Doolittles's queen-rearing methods. American Bee Journal, Hamilton, v. 39, n. 28, p. 435-436, 1899.

ISHIMOTO, E. Atividade antioxidante in vitro em vinhos e sucos de uva. 2003. 60 f. Dissertação (Mestrado em Nutrição) - Faculdade de Saúde Pública, Universidade de São Paulo, São Paulo. 2003.

INSTITUTO ADOLFO LUTZ. Métodos físico-químicos para análise de alimentos. São Paulo: Instituto Adolfo Lutz, 2008. 1020 p.

KERR, W. E.; AMARAL, E. Apicultura: científica e prática. São Paulo: Secretaria da Agricultura, 1960. 148 p.

KRELL, R. Pollen. In: KRELL, R. (Ed.). Value-added products from beekeeping. Roma, FAO Fiat Panis, 1996. Cap.3, p. 87-115 (FAO Agricultural Services Bulletin, 124).
JAMNIK, P.; GORANOVIC, D.; RASPOR, P. Antioxidative action of royal jelly in the yeast cell. Experimental Gerontology, Boulder, v. 42, p. 594-600, 2007.

MARCHINI, L. C. Geleia real: composição e produção. Zootecnia, Nova Odessa, v. 33, n. 1, p. 15-17, 1995.

MORGADO, L. N., BARRETO, C. F., FREITAS, A. S., BARTH, O. M. Espectro polínico de geleia real de Apis mellifera (Apidae: Apini) em Pindamonhangaba, São Paulo, Brasil. In: SIMPÓSIO DE PALEOBOTÂNICOS E PALINÓlOGOS, XII, 2008, Florianópolis. Anais... Porto Alegre: ALPP, 2008. Versão eletrônica. Disponível em $<$ http://www6.ufrgs.br/alpp/XII_SBPP Boletim_\%20de_Resumos.pdf $>$.

OLIVEIRA, K. C. L. S.; AZEVEDO, R. A. B; TEIXEIRA, E. W; ALVES, M. L. T. M. F.; MORETI, A. C. C. C.; MURADIAMALMEIDA, L. B. Efeito da desidratação do pólen apícola sobre o conteúdo de vitamina C. In: ENCONTRO SOBRE ABELHAS DE RIBEIRÃO PRETO, VII, 2006, Ribeirão Preto. Anais... Ribeirão Preto: FFCLRP-USP, FMRP-USP. 2006. CD-ROM.

RAMADAN, M. F.; AL-GHAMDIB, A. Bioactive compounds and health-promoting properties of royal jelly: A review. Journal of Functional Foods, St. John's, n. 4, p. 39-52, 2012.

SINGLETON, V. L.; ROSSI, J. A. JR. Colorimetry of total phenolics with phosphomolybdic-phosphotungstic acid reagents. American Journal of Enology and Viticulture, Davis, v. 16, p. $144-158,1965$. 